\title{
CONSIDERAÇÓES SOBRE A DECADÊNCIA CONTRA O BENEFICIÁRIO NO ÂMBITO DO DIREITO PREVIDENCIÁRIO
}

CONSIDERATIONS ABOUT THE DECADENCE AGAINST THE BENEFICIARY IN THE PENSION LAW AMBIT

Eduardo Levin

Defensor Público Federal

eduardo.levin@dpu.def.br

\section{RESUMO}

O presente trabalho visa abordar algumas questóes importantes sobre o instituto da decadência no Direito Previdenciário, no que diz respeito à decadência contra o beneficiário, não sendo incomuns as consultas dos assistidos da Defensoria Pública da União sobre suas possibilidades de revisão de seus benefícios, quando devemos obrigatoriamente enfrentar o tema, à luz da legislação vigente e da jurisprudência mais atual. Até 27 de junho de 1997, data da publicação da Medida Provisória no 1523-9/97, depois convertida na Lei no 9.528/97, a legislação previdenciária desconhecia o instituto da decadência. Tendo sido inserido no sistema um prazo para o exercício de direitos, por parte dos segurados, muitos foram os debates acerca da interpretação de sua verdadeira natureza, bem como sobre os contornos de sua aplicação às diversas situações que se apresentam na prática. Embora o Supremo Tribunal Federal, no julgamento do RE 626.489/SE, tenha pacificado alguns entendimentos sobre o tema, muitas outras questóes controvertidas continuam em aberto, como as referentes à aplicação do prazo de decadência nas açôes para reconhecimento de tempo de serviço ou contribuição, à aplicação do prazo de decadência para a revisão de benefício antecedente em caso de pensão por morte, à possibilidade de interrupção do prazo decadencial nos casos de requerimento administrativo, entre outras. $\mathrm{O}$ presente artigo procura trazer ao leitor o panorama atual do debate doutrinário e jurisprudencial sobre o tema.

Palavras-chave: Decadência. Benefícios. Revisão. Panorama. 


\section{ABSTRACT}

This paper aims to address some important questions about the institute of Lapsing in Social Security Law, regarding Lapsing against the beneficiary, and it is not uncommon to consult the assistants of the Public Defender's Office about their possibilities of reviewing their benefits, when we must tackle the issue in the light of current legislation and the most current jurisprudence. Until June 27, 1997, the date of publication of Provisional Measure no 1.523-9 / 97, later converted into Law no 9.528 / 97, the social security legislation was not aware of the institute of Lapsing. Since a period of time, for the exercise of rights by insured persons, has been included in the system, many debates about the interpretation of their true nature, as well as the contours of their application to the various situations, presented in practice. Although the Federal Supreme Court, in the judgment of RE 626.489 / SE, has pacified some understandings on the subject, many other controversial issues remain open, such as those concerning the application of the deadline of lapsing in the actions for recognition of time of service or contribution, application of the lapsing period for the review of antecedent benefit in case of death pension, the possibility of interruption of the lapsing period in the cases of administrative application, among others. The present article seeks to bring to the reader the current panorama of the doctrinal and jurisprudential debate on the subject.

Keywords: Lapsing. Benefits. Revision. Panorama.

Data de submissão: 27/02/2017

Data de aceitação: 06/06/2017

\section{SUMÁRIO}

INTRODUÇÃO 1. DECADÊNCIA CONTRA O BENEFICIÁRIO 2. A INCIDÊNCIA IMEDIATA DO NOVO PRAZO SOBRE BENEFÍCIOS CONCEDIDOS ANTERIORMENTE A SUA VIGÊNCIA 3. APLICAÇÃO DO PRAZO DE DECADÊNCIA NAS AÇÓES PARA RECONHECIMENTO DE TEMPO DE SERVIÇO OU CONTRIBUIÇÃO 4. APLICAÇÃO DO PRAZO DE DECADÊNCIA PARA A REVISÁO DE BENEFÍCIO ANTECEDENTE EM CASO DE PENSÁO POR MORTE 5. DA POSSIBILIDADE DE INTERRUPÇÃO DO PRAZO DECADENCIAL NOS CASOS DE REQUERIMENTO ADMINISTRATIVO. CONSIDERAÇÓES FINAIS 


\section{INTRODUÇÁO}

O significado da palavra decadência provém do latim cadens, de cadere (cair, perecer), assemelhando-se a caducidade, ou prazo extintivo ou preclusivo. Indica, do ponto de vista jurídico, a extinção do direito pelo decurso do prazo fixado para o seu exercício ${ }^{1}$. Sua aplicação decorre do princípio da segurança jurídica, tratando-se de verdadeira sanção oposta ao beneficiário da utilização de um direito material. ${ }^{2}$

A decadência, portanto, fulmina o direito, excluindo por via indireta qualquer possível pretensão do interessado. Refere-se a direitos potestativos, qualificáveis como aqueles mediante os quais determinadas pessoas podem influir, com uma declaraçáo de vontade, sobre situaçóes jurídicas de outras. Estes são, segundo a doutrina, direitos insuscetíveis de violação, pois a eles não corresponde qualquer prestação, sendo que o seu exercício, quando há necessidade de manifestação judicial, somente pode-se dar por açóes constitutivas (quando se procura obter a criação de um estado jurídico ou a modificação/extinção do estado anterior). ${ }^{3}$

No presente artigo, abordaremos algumas questóes importantes sobre o instituto da decadência na seara do Direito Previdenciário, em especial no que diz respeito à decadência contra o beneficiário. Trata-se de conclusóes advindas de consideraçóes e análises ventiladas no XI Congresso Brasileiro de Direito Previdenciário e I Congresso Ibero Americano de Direito Previdenciário, realizado no período de 07 a 09 de outubro de 2015, na cidade de Sáo Paulo/SP, do qual tive o privilégio de participar, como um dos representantes da Defensoria Pública da União.

O fenômeno da eventual demora do segurado em requerer a revisão de seu benefício previdenciário, após sua concessão na via administrativa, é questâo bastante relevante no âmbito de atuação da Defensoria Pública da União, não sendo incomuns as consultas de nossos assistidos sobre suas possibilidades de revisão de seus benefícios, quando devemos obrigatoriamente enfrentar o tema, à luz da legislação vigente e da jurisprudência mais atual. A decadência previdenciária afeta o direito do segurado em obter uma revisão benéfica do benefício, razão pela qual sua ocorrência ou não deve ser analisada a priori,

MARTINS, S. P. Direito da Seguridade Social, 2014, p. 277. 2015, p. 93

3 GONÇALVES, C. R. Direito Civil Brasileiro, 2006, p. 486-487. No mesmo sentido, GAGLIANO, P. S.; FILHO, R. P.. Novo curso de direito civil, 2013, p. 506-509 
qualquer que seja o pedido de revisão, sempre tendo em vista as exceçóes e nuances do instituto, quando aplicável no Direito Previdenciário.

Assim, após a apresentação do tema e do contexto normativo em que ele é tratado no Regime Geral de Previdência Social, será necessário fixar o âmbito de aplicação da decadência, tendo em vista, inclusive, a recente decisão do Tribunal Pleno do Supremo Tribunal Federal (RE 626.489/SE), que trouxe importantes balizamentos para a aplicação do instituto. Por fim, abordaremos casos excepcionais em que não haverá decadência, ainda que o prazo legal entre a concessão do benefício e o pedido de revisão tenha transcorrido.

\section{DECADÊNCIA CONTRA O BENEFICIÁRIO}

Até o dia 27 de junho de 1997, data da publicação da Medida Provisória no 1523-9/97, depois convertida na Lei no 9.528/97, a legislação previdenciária desconhecia o instituto da decadência. $\mathrm{O}$ artigo 103 da Lei no 8.213/91, tratava apenas da prescriçãó ${ }^{4}$. Criando a decadência em matéria previdenciária, a referida Medida Provisória fixou um prazo de decadência de dez anos "(...) de todo e qualquer direito ou açáo do segurado ou beneficiário para a revisão do ato de concessão de benefício, a contar do dia primeiro do mês seguinte ao do recebimento da primeira prestação ou, quando for o caso, do dia em que tomar conhecimento da decisão indeferitória definitiva no âmbito administrativo".

É de se mencionar que esse prazo chegou a ser reduzido para cinco anos pela Medida Provisória no 1663-15, convertida na Lei no 9.711/98. Posteriormente, no entanto, foi novamente restabelecido em dez anos, por força da Medida Provisória no ${ }^{\circ} 138 / 03$, convertida na Lei no $10.839 / 04$. Como o prazo de cinco anos náo chegou a se aperfeiçoar, já que a Lei no 9.711/98 é de 20 de novembro de 1998 e a Medida Provisória no 138/03 é de 19/11/2003, entende Marcelo Leonardo Tavares que esse prazo de cinco anos deve ser desconsiderado, o que faz com que o prazo decadencial seja um só, de dez anos, contados desde a criação da Medida Provisória no 1523-95.

Pois bem.

\footnotetext{
Eis a redação original do artigo 103, da Lei no 8.213/91: "Sem prejuízo do direito ao benefício, prescreve em 5 (cinco) anos o direito às prestaçóes náo pagas nem reclamadas na época própria, resguardados os direitos dos menores dependentes, dos incapazes ou dos ausentes."

5 TAVARES, M. L. Direito Previdenciário: regime geral de previdência social e regras constitucionais dos regimes próprios de previdência social, 2015, p. 251. Com o mesmo entendimento, CASTRO, C. A. P. de; LAZZARI, J. B. Manual de Direito Previdenciário, 2014, p. 911
} 
A redação atual do artigo 103, da Lei no 8.213/91, é a seguinte:

“Art. 103. É de dez anos o prazo de decadência de todo e qualquer direito ou ação do segurado ou beneficiário para a revisão do ato de concessão de benefício, a contar do dia primeiro do mês seguinte ao do recebimento da primeira prestação ou, quando for o caso, do dia em que tomar conhecimento da decisão indeferitória definitiva no âmbito administrativo.

Parágrafo único. Prescreve em cinco anos, a contar da data em que deveriam ter sido pagas, toda e qualquer ação para haver prestaçóes vencidas ou quaisquer restituiçóes ou diferenças devidas pela Previdência Social, salvo o direito dos menores, incapazes e ausentes, na forma do Código Civil."

Da análise do dispositivo decorre, em primeiro lugar, no que tange à decadência, que se um benefício não foi requerido, não corre prazo decadencial algum, porque a Lei não fixa prazo para o exercício do direito potestativo ao requerimento (a partir do momento em que o segurado implementa os requisitos para a percepção do benefício). A decadência, conforme dispóe a norma, atinge apenas duas situaçóes: a revisão do ato de concessão do benefício e a impugnação da decisão indeferitória definitiva no âmbito administrativo. ${ }^{6}$

Ocorre que a aplicação pura e simples do dispositivo em questão, em especial quando o segurado deseja impugnar decisão que indeferiu o pedido de concessão do benefício, provocaria grandes injustiças. Isso porque nos casos em que o segurado implementa as condiçóes para perceber o benefício mas não o requer, poderá fazê-lo após dez anos sem que seu direito tenha caducado, ao passo que nos casos em que o benefício foi requerido mas foi negado pelo INSS, o segurado perderá o direito ao benefício após dez anos. Ou seja, a literalidade da norma está, em verdade, protegendo o mais negligente, aquele que atuou contrariamente ao objetivo de estabilidade e pacificação social, pois é melhor deixar de requerer o benefício - deixando em aberto ad eternum essa possibilidade -, do que requerê-lo e tê-lo negado - caso em que o segurado somente terá dez anos para pedir a revisão do ato administrativo que negou o benefício, sob pena de perder o fundo de direito, isto é, o próprio direito ao benefício.

Por essa razão, alguns doutrinadores, como Marcelo Leonardo Tavares ${ }^{7}$ e Fabio Zambitte

6 VIANNA, J. E. A. Curso de Direito Previdenciário, 2014, p. 613.

7 TAVARES, Marcelo Leonardo. Direito Previdenciário: regime geral de previdência social e regras constitucionais dos regimes próprios de previdência social, 2015, p. 249 
Ibrahim, ${ }^{8}$ têm o entendimento de que o prazo previsto no caput do artigo 103, da Lei $\mathrm{n}^{\circ} 8.213 / 91$, possui em verdade natureza prescricional, apesar da literalidade da norma. Ou seja, o fundo de direito, a relação jurídica essencial que embasa o pedido, para esses doutrinadores, não se perderia com o decurso do tempo, o que ocorreria é a perda do direito de ver o benefício concedido com base na mesma data de início (DIB) e sob os mesmos pressupostos.

Por esse entendimento, nada impediria, por exemplo, que o segurado que pleiteou aposentadoria por tempo de contribuição em fevereiro de 2000, sem êxito, venha a requerê-la novamente em março de 2011, dessa vez com novas provas de tempo de contribuição (exercido anteriormente a fevereiro de 2000). Se lograr êxito, com seu novo requerimento, em comprovar o tempo de contribuição necessário à aposentação, esta deverá lhe ser concedida, com DIB em março de 2011, pois o fundo de direito não teria sido perdido, apenas o direito aos valores atrasados, a contar de fevereiro de 2000 , é que se encontrariam prescritos.

Aliás, como bem ressaltado por Fabio Zambitte Ibrahim, ${ }^{9}$ o próprio Regulamento da Previdência Social (Decreto no 3.048/99), em seu artigo 347, $\$ 2^{\circ}$, assevera que não se considera pedido de revisão, mas sim nova solicitação de benefício, o requerimento que vier acompanhado de outros documentos além dos já existentes no processo.

Portanto, referido entendimento nos parece correto, pois ao mesmo tempo em que não exclui a eficácia jurídica da norma, mantendo-se a sanção pela inércia do titular (qual seja, a de náo fazer jus a qualquer pagamento retroativo ao requerer novo benefício, após o prazo de dez anos do pedido anterior), preserva o fundo de direito referente ao benefício previdenciário, que deriva de uma garantia constitucional com natureza de direito fundamental (dignidade da pessoa humana), devendo ser interpretado dentro das condicionantes constitucionais da universalidade de cobertura e atendimento. ${ }^{10}$

Náo obstante, o Supremo Tribunal Federal, no julgamento do RE 626.489/SE, da relatoria do Min. Luís Roberto Barroso, não acatou o argumento de que a natureza

8 IBRAHIM , Fábio Zambitte. Curso de Direito Previdenciário, 2014, p. 421. Segundo o autor, "Indica a lei prazo para o ingresso de açáo condenatória contra o INSS, visando a garantia de um direito a uma prestação, espécie de direito subjetivo distinto do direito potestativo. Em razáo de tal natureza, deve-se privilegiar o espírito em detrimento da letra da lei, pois há na lei um evidente prazo prescricional". Com o mesmo entendimento, CASTRO, Carlos Alberto Pereira de; LAZZARI, João Batista. Manual de Direito Previdenciário, 2014, p. 913.

10 Mais uma vez, IBRAHIM, Fábio Zambitte. Curso de Direito Previdenciário, 2014, p. 424. 
do prazo previsto no referido artigo 103 da Lei no 8.213/91 é prescricional. Embora tenha pacificado o entendimento de que náo há prazo decadencial para a formulaçáo do requerimento inicial de concessão de benefício previdenciário, por corresponder a um exercício de direito fundamental relacionado à mínima segurança social do indivíduo (não fazendo menção específica ao caso em que o beneficio é requerido e negado), acabou por confirmar a natureza decadencial do prazo de dez anos previsto na referida norma, aplicável, conforme o Excelso Pretório, para a revisão dos benefícios já concedidos. ${ }^{11}$

Frise-se, no entanto, que o Supremo Tribunal Federal nada disse em relação à situação em que o benefício é requerido e negado, apenas confirmando a aplicação do prazo decadencial para a revisão de benefícios requeridos e concedidos. Assim, a celeuma quanto à existência ou não de um prazo decadencial para o pedido de revisão do ato administrativo que indeferiu o benefício permanece viva, sendo o nosso entendimento (em concordância com os doutrinadores já citados) no sentido de que tal situação se assemelha à hipótese em que o benefício sequer é requerido (apesar de ter o segurado preenchido os requisitos), razão pela qual tanto neste como naquele caso não há que se falar em decadência, pois ambas as situaçóes são muito semelhantes e correspondem "ao exercício de um direito fundamental relacionado à mínima segurança social do indivíduo", conforme decidido pelo Excelso Pretório. ${ }^{12}$

A Súmula 81 da Turma Nacional de Uniformização dos Juizados Especiais Federais também agasalha essa posição: "Não incide o prazo decadencial previsto no art. 103, caput, da Lei n. 8.213/91, nos casos de indeferimento e cessação de benefícios, bem como em relação às questōes não apreciadas pela Administração no ato da concessão". Nesse mesmo sentido, a orientação do STJ: AgRg no AREsp no 493.997/PR, 2a Turma, Rel. Min. Mauro Campbell Marques, DJe 9.6.2014: AgRg no REsp 1.407.710/PR, 2a Turma,

\footnotetext{
11 Transcrevemos o trecho pertinente do referido acórdão: “(...) 15. No encerramento deste tópico, é possível sintetizar os dois parâmetros gerais que devem reger a matéria: a) não há prazo decadencial para a formulação do requerimento inicial de concessão de benefício previdenciário, que corresponde ao exercício de um direito fundamental relacionado à mínima segurança social do indivíduo; b) a instituição de um prazo decadencial de dez anos para a revisão dos benefícios já concedidos é compatível com a Constituição Federal. Trata-se de uma conciliaçáo razoável entre os interesses individuais envolvidos e os princípios da segurança jurídica e da solidariedade social, dos quais decorre a necessidade de se preservar o equilíbrio atuarial do sistema em benefício do conjunto de segurados atuais e futuros." (RE 626.489/SE, Pleno, unânime, 16/10/2013) 12 Este também é o entendimento de Gustavo Filipe Barbosa Garcia, in verbis: "A correta interpretação do art. 103 da Lei 8.213/1991, portanto, é no sentido de que o prazo decadencial de dez anos abrange a decisão administrativa que concedeu o benefício previdenciário, bem como o ato administrativo que estabeleceu o seu valor inicial, mas não alcança a decisão administrativa de cessação ou de indeferimento, em si, do benefício propriamente. Mesmo porque o direito ao benefício previdenciário, de natureza fundamental, pode ser exercido a qualquer tempo". GARCIA, Gustavo Filipe Barbosa. Curso de Direito da Seguridade Social, 2015, p. 508.
} 
Rel. Min. Herman Benjamin, DJe 22.5.2014.

\section{A INCIDÊNCIA IMEDIATA DO NOVO PRAZO SOBRE BENEFÍCIOS CONCEDIDOS ANTERIORMENTE A SUA VIGÊNCIA}

Outro problema que se originou a partir da referida inovação legislativa tem que ver com a aplicação da lei no tempo. É preciso definir se a norma que inaugurou a decadência, contra o beneficiário, no âmbito do Direito Previdenciário, aplica-se ou não aos benefícios concedidos antes da Medida Provisória no 1523-9, de 27/06/1997.

O Superior Tribunal de Justiça chegou a firmar jurisprudência no sentido de que os benefícios concedidos antes da criação do prazo de revisão não se submeteriam a qualquer prazo decadencial, aos fundamentos de que a Medida Provisória no 1.523/1997 não previu expressamente a retroação de seus efeitos, e considerando que a decadência é instituto de direito material (AgRg no Ag 847451/RS, de 23/10/2007, 6a Turma; AgRg no REsp 1291918 / PE, 17/04/2012, 5a Turma).

No entanto, a Primeira Seção da Corte, no julgamento do REsp 1.303.988/PE, de relatoria do Min. Teori Albino Zavascki, por unanimidade, modificou o entendimento até então pacífico, para reconhecer que o prazo decadencial disposto na nova redação do art. 103, caput, da Lei n. 8.213/91, embora não possa retroagir para incidir sobre o tempo transcorrido antes de sua vigência, tem sua eficácia a partir da entrada em vigor da nova norma, aplicando-se aos benefícios concedidos anteriormente a contar da data de publicação da Medida Provisória n. 1.523-9, de 27.6.1997.

No que diz respeito à doutrina, percebe-se uma corrente majoritária que caminha no sentido de sufragar este último entendimento do Colendo Superior Tribunal de Justiça, entre outros motivos por conta da impossibilidade de que todos os segurados aposentados anteriormente à inovação legal tenham direito adquirido à não aplicação do prazo decadencial, pois esse prazo não é elemento constitutivo do direito subjetivo. ${ }^{13}$

$\overline{13}$ IBRAHIM, F. Z. Curso de Direito Previdenciário, 2014, p. 425; TAVARES, M. L. Direito Previdenciário: regime geral de previdência social e regras constitucionais dos regimes próprios de previdência social, 2015, p. 252; CASTRO, C. A. P. de; LAZZARI, J. B. Manual de Direito Previdenciário, 2014, p. 913; VIANNA, J. E. A.. Curso de Direito Previdenciário, 2014, p. 613; GARCIA, G. F. B. Curso de Direito da Seguridade Social, 2015, p. 508-509. Em sentido contrário, RUBIN, F. Aposentadorias Previdenciárias no Regime Geral da Previdência Social, 2015, p. 105-106. 
Sobre o tema, o Supremo Tribunal Federal, no julgamento do mesmo RE 626.489/ $\mathrm{SE}$, sedimentou o entendimento de que, como a decadência náo integra o espectro de pressupostos e condiçóes para a concessão do benefício, eventuais alteraçóes posteriores quanto a tal elemento devem ter incidência imediata, sem que se cogite de ofensa a direito adquirido. Assim, o novo prazo deve ser aplicado aos benefícios concedidos anteriormente a sua vigência, mas como a lei nova não tem efeitos retroativos, entendeu o Excelso Pretório que ela deve ser aplicada de forma imediata, inclusive quanto às situaçóes constituídas no passado, devendo o termo inicial do novo prazo ser o momento da vigência da nova lei. ${ }^{14}$

Ou seja, resta pacificado que o prazo decadencial de dez anos, instituído pela Medida Provisória $\mathrm{n}^{\circ} 1.523$, de 28/06/1997, incide, inclusive, sobre benefícios concedidos anteriormente, sem que isso importe em retroatividade vedada pela Constituição. No entanto, é preciso observar que há situações em que esse prazo não se aplica, como nos casos de reconhecimento de tempo de serviço/contribuição, na revisão de benefício antecedente requerida pelo beneficiário da pensão por morte, no pedido de desaposentação e nos casos em que há interesse de absolutamente incapaz para os atos da vida civil, entre outras hipóteses.

\section{APLICAÇÁO DO PRAZO DE DECADÊNCIA NAS AÇÓES PARA RECONHECIMENTO DE TEMPO DE SERVIÇO OU CONTRIBUIÇÁO}

Se pensarmos numa ação meramente declaratória objetivando a averbaçấo do tempo de serviço/contribuição, é evidente que não há que se falar em prescrição ou decadência, pois inexiste cunho patrimonial imediato, apenas se objetiva a declaração de existência de uma relação jurídica. ${ }^{15}$ A polêmica surge, no entanto, nos casos das ações de natureza

\footnotetext{
14 Eis a ementa: RECURSO EXTRAODINÁRIO. DIREITO PREVIDENCIÁRIO. REGIME GERAL DE PREVIDÊNCIA SOCIAL (RGPS). REVISÃO DO ATO DE CONCESSÃO DE BENEFÍCIO. DECADÊNCIA. 1. O direito à previdência social constitui direito fundamental e, uma vez implementados os pressupostos de sua aquisição, não deve ser afetado pelo decurso do tempo. Como consequência, inexiste prazo decadencial para a concessão inicial do benefício previdenciário. 2. É legítima, todavia, a instituição de prazo decadencial de dez anos para a revisão de benefício já concedido, com fundamento no princípio da segurança jurídica, no interesse em evitar a eternização dos litígios e na busca de equilíbrio financeiro e atuarial para o sistema previdenciário. 3. O prazo decadencial de dez anos, instituído pela Medida Provisória 1.523, de 28.06.1997, tem como termo inicial o dia $1^{\circ}$ de agosto de 1997, por força de disposição nela expressamente prevista. Tal regra incide, inclusive, sobre benefícios concedidos anteriormente, sem que isso importe em retroatividade vedada pela Constituição. 4. Inexiste direito adquirido a regime jurídico náo sujeito a decadência. 5. Recurso extraordinário conhecido e provido.
}

(REsp 626489/SE, Rel. Ministro Luís Roberto Barroso, Pleno, julgado em 16/10/2013, DJe 23/09/2014) 
condenatória, cuja inclusão do período trabalhado é requerida visando à revisão do benefício já concedido.

Se o segurado, já aposentado, ingressa em juízo, após dez anos do pagamento da primeira prestação, postulando o reconhecimento de tempo trabalhado, por exemplo, em condiçóes especiais, para aumentar o coeficiente de cálculo de seu benefício, e com isso rever o ato de concessão do benefício, surge então o questionamento: aplica-se o prazo de decadência que impede a revisão proposta?

Na visão de Carlos Alberto Pereira de Castro, João Batista Lazzari, ${ }^{16}$ Daniel Machado da Rocha e José Paulo Baltazar Júnior, ${ }^{17}$ com os quais concordamos, a aplicação da decadência nesse caso esbarraria na regra do direito adquirido, por conta das características intrínsecas do direito à contagem e averbação do tempo de serviço/contribuição, conforme a lei vigente à época em que efetivamente prestado, passando a integrar, como direito autônomo, o patrimônio jurídico do trabalhador.

Como fundamento ao referido entendimento, Carlos Alberto Pereira de Castro e João Batista Lazzari ${ }^{18}$ trazem à baila, de modo absolutamente pertinente, decisão do Supremo Tribunal Federal que pode servir de paradigma, relativa ao exame do direito à contagem do tempo de serviço especial prestado por servidor público ex-celetista. No RE 380413 $\mathrm{AgR} / \mathrm{PB}$, a Corte Constitucional entendeu que a contagem de tempo de serviço prestado por servidor público ex-celetista em condições insalubres, em período anterior à Lei $8.112 / 90$, constitui direito adquirido para todos os efeitos.

Segundo o Ministro Relator Eros Roberto Grau:

tendo exercido suas atividades funcionais em condiçôes insalubres à época em que submetido aos regimes celetista e previdenciário, o servidor público possui direito adquirido à contagem desse tempo de serviço de forma diferenciada e para fins de aposentadoria. Em cada momento trabalhado realizava-se o suporte fático previsto no texto normativo como suficiente a autorizar sua averbação. Sendo assim, é incorporado ao seu patrimônio jurídico direito que a legislação específica lhe assegurava como compensaçáo pelo serviço exercido em condiçốes insalubres, periculosas ou penosas. Essa vantagem não pode ser suprimida mercê do advento de um novo regime jurídico

\footnotetext{
$\overline{16}$ CASTRO, C. A. P. de; LAZZARI, J. B. Manual de Direito Previdenciário, 2014, p. 915-916; 17 ROCHA, D. M. da; BALTAZAR JÚNIOR, J. P. Comentários à lei de benefícios da previdência social, 2001, p. 329.

18 CASTRO, C. A. P. de; LAZZARI, J.B. Manual de Direito Previdenciário, 2014, p. 916.
} 
que, apesar de prever a edição de lei específica para regulamentar a concessão de aposentadoria para os agentes públicos que exerçam atividades nessas condiçóes, não desconsiderou ou desqualificou o tempo de serviço prestado ao tempo da legislação anterior. ${ }^{19}$

Assim, defendemos que a decadência náo pode ferir o direito adquirido do segurado de ter averbado o tempo trabalhado em qualquer época, sendo possível a proprositura de ação para revisão de benefícios concedidos há mais de dez anos, se o objeto for a agregação de tempo de contribuição. Como reforço argumentativo a essa posição, pode-se mencionar o artigo $11, \$ 1^{\circ}$, da CLT, que trata da prescrição do direito de ação decorrente das relaçóes de trabalho, estabelecendo que as açôes manejadas à obtenção de anotaçôes destinadas a fazer prova perante a previdência social são imprescritíveis. ${ }^{20}$

Isso deve valer também para os casos em que se objetiva revisar o benefício com base em sentença trabalhista que reconhece períodos trabalhados em condiçóes especiais, ou tempo de trabalho urbano ou rural, por exemplo, pelos mesmos fundamentos, conforme, inclusive, vem entendendo o STJ (Cf. REsp. no 1440868/RS, 2a Turma, Rel. Min. Mauro Campbell Marques, julgado em 24.4.2014, DJe 2.5.2014).

\section{APLICAÇÁO DO PRAZO DE DECADÊNCIA PARA A REVISÁO DE BENEFÍCIO ANTECEDENTE EM CASO DE PENSÁO POR MORTE}

Caso o beneficiário tenha perdido, em vida, o direito de solicitar a revisão do valor de sua aposentadoria, o direito poderá ser discutido pelo pensionista, ainda que fundado em dados que poderiam ter sido questionados pelo aposentado atingido pela decadência. Isso é o que restou decidido pela Turma Nacional de Uniformização dos Juizados Especiais Federais, no Pedido de Uniformização no 2008.50.51.001325-4:

"PROCESSUAL CIVIL PREVIDENCIÁRIO. PENSÃO POR MORTE DERIVADA DE BENEFÍCIO PREVIDENCIÁRIO. DIREITO DE REVISÃO. PRAZO DECADENCIAL AUTÔNOMO. CÔMPUTO DO PRAZO A PARTIR DA CONCESSÃO DA PENSÃO. INCIDENTE IMPROVIDO."

\footnotetext{
$19 \quad$ RE 380413, Rel. Ministro Eros Grau, 2a Turma, DJe de 29/06/2007)

20 CASTRO, Carlos Alberto Pereira de; KRAVCHYCHYN, Gisele Lemos; KRAVCHYCHYN, Jefferson Luis; LAZZARI, João Batista. Prática Processual Previdenciária - Administrativa e Judicial, 2016, p. 648.
} 
1. Pedido de concessão de revisão da renda mensal inicial do benefício previdenciário de pensão concedido em 09/11/1998, originário de benefício concedido em 16/03/1994, mediante a aplicação da variação integral do IRSM de fevereiro de 1994 (39,67\%) na composição do índice de atualização dos salários-de-contribuiçãao anteriores a março de 1994, antes da conversão dos valores em URV.

2. Sentença de procedência do pedido.

3. Recurso inominado do INSS apenas no que diz à decadência do direito. A Turma Recursal da Seção Judiciária do Espírito Santo manteve a sentença referindo que o prazo decadencial deve ser considerado em razão da data de início da pensão por morte e náo do benefício do instituidor da pensão. Considerou, ainda, que se o instituidor/aposentado perdeu, em vida, o direito de revisar o ato de concessão da sua aposentadoria-base, esse fato não prejudica o titular da subseqüente pensão por morte, o qual pode discutir amplamente todos os critérios que tenham influenciado o cálculo do seu benefício, ainda que fundados em dados que poderiam ter sido questionados pelo aposentado atingido pela decadência.

4. Incidente de uniformização de jurisprudência, interposto pelo INSS, com fundamento no art. $14, \$ 2^{\circ}$, da Lei no $10.259 / 2001$.

5. Alegação de que o acórdão recorrido diverge do entendimento da Turma Recursal da Seção Judiciária do Paraná (2007.705.001.94771), destacando que o prazo decadencial iniciado contra o instituidor do benefício continua a correr contra o sucessor.

6. Incidente admitido na origem.

7. Seguindo a linha de raciocínio perfilhado pela Magistrada Simone Lemos Fernandes, nos autos do PREDILEF n. 2009.72.54.0039637. julgado em 29 de março de 2012, considero que a pensão por morte e o benefício previdenciário do qual deriva são, de fato, benefícios atrelados por força do critério de cálculo de ambos, tão somente. Mas são benefícios autônomos, titularizados por pessoas diversas que, de forma independente, possuem o direito de requerer a revisão de cada um deles, ainda que através de sucessores (pois a pensão por morte pressupóe, logicamente, o falecimento de seu instituidor), sendo que o prazo decadencial de revisão da pensão começa fluir a partir da data da concessão. Certo que os sucessores de segurado já falecido podem requerer, judicialmente, o reconhecimento de parcelas que seriam devidas àquele por força de incorreto cálculo de seu benefício. Mas não é este o tema discutido nestes autos, já que a autora náo postulou diferenças sobre a aposentadoria de seu falecido marido, mas tão somente diferenças sobre a pensão por morte que percebe. 
8. Dessa forma, considero que existe prazo decadencial autônomo, diferenciado, relativo ao direito de revisão da pensão por morte percebida pela autora, computado a partir da data de sua concessão, o qual foi concedida em 09/11/1998. Outrossim, ressalto que, embora não seja o caso dos autos, alhures mencionado, a decadência do direito de revisão da aposentadoria propriamente dita, concedida ao falecido esposo da autora em março de 1994, encontra-se suspensa por repercussão geral (benefício concedido antes de 1997).

9. In casu, como a parte autora começou a perceber benefício em novembro de 1998, o prazo decadencial decenal começou a fluir a partir do primeiro dia do mês subsequente ao do recebimento da primeira prestação, consoante regra prevista no art. 103 da Lei n. $8.213 / 91$, não se consumou a decadência.

10. Ante o exposto, voto por reafirmar o entendimento de que existe prazo decadencial autônomo, diferenciado, relativo ao direito de revisão da pensão por morte, computado a partir da data de sua concessão, e para negar provimento ao incidente de uniformização interposto pelo INSS.

11. Sugiro ao eminente Presidente desta Turma que imprima, ao resultado desse julgamento, a sistemática prevista no art. $7^{\circ}$, VII, 'a', do RITNU.” (TNU, PU no 2008.50.51.001325-4, Relator: Adel Américo Dias de Oliveira, DJ: 27/06/2012)

Ou seja, os beneficiários da pensão por morte não poderão sofrer os reflexos da falta de revisão do benefício de origem. O prazo decadencial para a revisão da pensão, nesses casos, conta-se a partir do início do recebimento desta, ainda que o fundamento da revisão seja o recálculo do benefício que era recebido pelo de cujus.

Observe-se que contra o absolutamente incapaz, nos termos do artigo $3^{\circ}$, do Código Civil (menores de 16 anos), não corre decadência, tendo em vista o disposto no artigo 198, I, combinado com o artigo 208, todos também do Código Civil. Portanto, sendo o pensionista absolutamente incapaz ao tempo da morte do instituidor da pensão, apenas quando ele completar 16 anos é que terá início o prazo decadencial, de dez anos, para o pedido de revisão da pensão por morte. 


\section{DA POSSIBILIDADE DE INTERRUPÇÁO DO PRAZO DECADENCIAL NOS CASOS DE REQUERIMENTO ADMINISTRATIVO}

Entre as diversas dúvidas surgidas com a criação da decadência, está a que se refere à aplicação de interpretação do disposto na parte final do caput do já mencionado artigo 103:

É de dez anos o prazo de decadência de todo e qualquer direito ou ação do segurado ou beneficiário para a revisão do ato de concessão de benefício, a contar do dia primeiro do mês seguinte ao do recebimento da primeira prestaçáo ou, quando for o caso, do dia em que tomar conhecimento da decisão indeferitória definitiva no âmbito administrativo.

Concordamos com a doutrina que reconhece que tal redação criou a possibilidade legal de interrupção do prazo decadencial quando o beneficiário ingressar com o pedido administrativo de revisão do benefício, na medida em que não poderá haver decadência quando o titular do direito atua no sentido de sua proteção, já que ausente, aí, o principal requisito do instituto: a inércia do titular. ${ }^{21}$ Aliás, nada obsta que a lei crie prazos interruptivos para a decadência, algo que está expressamente permitido pelo artigo 207 do Código Civil vigente. ${ }^{22}$

Destaca-se que a contagem do prazo decadencial, em caso de interrupção, se reinicia sem qualquer utilização do tempo anteriormente transcorrido, "primeiro porque essa é a regra geral das normas de interrupção de prazo e segundo porque não cabe à espécie interpretação restritiva do direito do segurado, por estarmos tratando de direito social" ${ }^{23}$ Assim, se, por exemplo, o segurado recebeu o primeiro pagamento de seu benefício em 01/02/2001 (prazo para a revisão se encerraria em 01/03/2011), mas requereu administrativamente a revisão em 20/02/2011, um novo prazo decadencial, de dez anos, terá início, após a negativa final na esfera administrativa (se ele for notificado, por exemplo, em 20/02/2013, terá até 20/02/2023 para requerer a revisão judicialmente).

Essa questão foi expressamente abordada pela Turma Regional de Uniformização

$\overline{21}$ CASTRO, C. A. P. de; KRAVCHYCHYN, G. L.; KRAVCHYCHYN, Jefferson Luis; LAZZARI, João Batista. Prática Processual Previdenciária - Administrativa e Judicial, 2016, p. 655.

22 "Artigo 207. Salvo disposiçáo legal em contrário, não se aplicam à decadência as normas que impedem ou interrompem a prescrição"

23 CASTRO, C. A. P. de; KRAVCHYCHYN, G. L.; KRAVCHYCHYN, Jefferson Luis; LAZZARI, João Batista. Prática Processual Previdenciária - Administrativa e Judicial, 2016, p. 657. 
da $4^{\text {a }}$ Região, tendo sido confirmada essa posição aqui defendida (IUJEF 000432407.2010.404.7252/SC, Rel. Juíza Federal Ana Cristina Monteiro de Andrade Silva, Sessão 20.07.2012).

\section{CONSIDERAÇÓES FINAIS}

Diante de todas essas observaçóes, o que se percebe, em suma, é que, afora as questóes da aplicação do prazo decadencial aos benefícios concedidos anteriormente à publicação da Medida Provisória no 1523-9/97, com início a partir da vigência desta, e da não aplicação deste prazo decadencial para a formulação do requerimento inicial de concessão de benefício previdenciário, por corresponder a um exercício de direito fundamental relacionado à mínima segurança social do indivíduo, já sacramentadas pelo Supremo Tribunal Federal, os contornos do instituto da decadência no Direito Previdenciário ainda carecem de maior definição quanto à sua aplicação.

Esta foi a conclusão que extraímos a partir das pesquisas doutrinárias e jurisprudenciais realizadas, bem como das palestras e debates ocorridos no ensejo do já referido XI Congresso Brasileiro de Direito Previdenciário e I Congresso Ibero Americano de Direito Previdenciário, realizado no período de 07 a 09 de outubro de 2015, na cidade de São Paulo/SP, cuja participação deste que subscreve motivou a produção deste artigo.

Não resta dúvida de que não é possível simplesmente aceitarmos, em prejuízo dos nossos assistidos, as frequentes negativas de revisão de seus benefícios, pelo INSS, sob o argumento genérico da decadência, pois, como visto, várias são as situaçóes em que a aplicaçáo pura e simples do que dispóe o artigo 103, caput, da Lei no 8.213/91, não é a soluçấo adequada do ponto de vista jurídico e social, lembrando que as exceçôes e exemplos aqui trazidos não esgotam o tema. 


\section{REFERÊNCIAS}

AURÉLIO, B. Atos administrativos ampliativos de direitos, revogaçáo e invalidaçáo. São Paulo: Malheiros, 2011.

CASTRO, C. A. P.; LAZZARI, J. B. Manual de Direito Previdenciário. 16.ed. Rio de Janeiro: Forense, 2014.

CASTRO, C. A. P. de; KRAVCHYCHYN, G. L.; KRAVCHYCHYN, J. L.; LAZZARI, João Batista. Prática Processual Previdenciária - Administrativa e Judicial. 8. Ed. Rio de Janeiro: Forense, 2016.

DI PIETRO, M. S. Z. Direito Administrativo. 26.ed. São Paulo: Atlas, 2013.

DINIZ, M. H. Curso de direito civil brasileiro. 31.ed. v.I., São Saraiva, 2014.

GAGLIANO, P. S.; FILHO, R. P. Novo curso de direito civil. 15.ed. v.I, São Paulo: Saraiva, 2013.

MARTINEZ, W. N. Cobrança de benefícios indevidos. São Paulo: LTr, 2012.

MELLO, C. A. B. de. Curso de direito administrativo. 29.ed. São Paulo: Malheiros, 2012.

. Grandes temas de direito administrativo. 1.ed. São Paulo: Malheiros, 2010.

MENDES, G. F.; BRANCO, P. G. G. Curso de direito constitucional. 6.ed. São Paulo: Saraiva, 2011.

MOREIRA, E. B. As Várias Dimensóes do Processo Administrativo Brasileiro (um Direito-Garantia Fundamental do Cidadão). In: MELLO, C. A. B. de; FERRAZ, S.; ROCHA, S. L. F. da e SAAD, A. F. (Coord.). Direito administrativo e liberdade: estudos em homenagem a Lúcia Valle Figueiredo. São Paulo: Malheiros, 2014.

PETIAN, A. Regime Jurídico dos Processos Administrativos Ampliativos e Restritivos de Direito. São Paulo: Malheiros, 2011. 
PONTES DE MIRANDA, F. C. Tratado de Direito Privado. t.IV. Atualizada por MELLO, M. B. de e EHRHARDT, M.. São Paulo: RT, 2013.

SUNDFELD, C. A. Fundamentos de Direito Público. 4.ed. São Paulo: Malheiros, 2005.

VALIM, R. O Princípio da Segurança Jurídica no Direito Administrativo Brasileiro. São Paulo: Malheiros, 2010.

VENOSA, S. de S. Direito Civil. 14.ed. v.I., São Paulo: Atlas, 2014.

ZANCANER, W. Da Convalidaçáo e da Invalidaçáo dos Atos Administrativos. 3.ed. São Paulo: Malheiros, 2008. 